\title{
Induced Suppressiveness to Fusarium oxysporum with Phytostimulation Microorganisms (PSMs) in Hydroponically Grown Tomato
}

Hassanein, N.M ; El-Kattan, M.H ${ }^{2}$; El-Behairy, U.A.A ${ }^{3}$. and Shafik, D.A ${ }^{4}$.

1- Department of Microbiology, Faculty of Science, Ain Shams University, Cairo, Egypt

2- Agricultural Microbiological Research Department, Soil, Water and Environment Research Institute, Agricultural Research Center, Giza, Egypt

3- Department of Horticulture, Faculty of Agriculture, Ain Shams University, Cairo, Egypt.

4- Central Lab. for Agricultural Climate, Agricultural Research Center, Dokki, 12411, Giza, Egypt.

Dhytostimulation microorganisms $\left(\mathrm{PSM}_{\mathrm{s}}\right)$ vis. Bacillus subtilis, Bacillus polymyxa and Trichoderma harzianum were tested for their ability to suppress and control Fusarium root rot in tomato plants grown in sterilized soilless medium artificially infested with Fusarium oxysporum f. sp. radicis-lycopersici (FORL). Antagonistic activities under laboratory conditions were detected at various degrees of the PSM $_{\mathrm{s}}$ against $F$. oxysporum. $T$. harzianum was the most potent antagonist and gave an inhibition value of $62 \%$. T. harzianum was also the most effective in decreasing the percentage of pre-emergence damping-off $(50 \%)$ while $B$. polymyxa was the most effective one in decreasing the post-emergence $(3 \%)$ under greenhouse conditions. PSMs were used as seeds soaking or seedlings inoculation of tomato plants. Pathogenicity test showed that seedlings were more susceptible to $F$. oxysporum than seeds. PSMs-treated seeds showed that $T$. harzianum was the superior in controlling Fusarium root rot disease (93\% disease control percentage) while in case of seedlings inoculation, B. subtilis gave the highest disease control value $(73.3 \%)$. B. subtilis and B. polymyxa treated seeds or seedlings were the superior in improving most growth parameters tested in both cases compared to the controls. These results suggest that the increasing of disease control and improvement of tomato growth parameters by seeds or seedlings inoculation with PSMs may contribute to protection of tomato plants against $F$. oxysporum root rot disease.

Keywords: Tomato, Solanum lycopersicum, Trichoderma harzianum, Bacillus subtilis, Bacillus polymyxa, Fusarium oxysporum, Phytostimulation, Hydroponic.

Tomato production with intensive systems is increasingly using potting culture with organic substrates. One of the tomato crop problems is Fusarium wilt and root rot which cause important yield losses, and for these problems there are no effective chemical control measures. However, biological control is becoming an efficient alternative for controlling these diseases (Borrero et al., 2005). Some growth media formulated with composts can suppress Fusarium wilt and root rot with respect to 
peat (Trillas et al., 2002). The nature of soils and composts with suppressiveness to Fusarium wilt and root rot is the result of complex interactions between the abiotic characteristics of the media and microbial populations (Weller et al., 2002 and Borrero et al., 2004). Several biocontrol agents have been identified in these soils and composts (Weller et al., 2002).

Hydroponic system (soilless culture) is cultivating the crops in nutrient solution or media without soil or is the production of crops isolated from the soil either with or without a medium, with their total water and nutrient requirements supplied by the system (Hunger, 1979).

Meanwhile, hydroponic system can also be applied for improving food security and more specifically in small-scale urban horticulture. In this concern, the main reasons are the lack of fertile soil, or space as well as the need to produce safe vegetables to avoid health hazards. The needs of soilless culture will increase rapidly because of the limited water resources, organic manures and rapid increase in population (Baudoin et al., 1990).

Hydroponic systems can be classified according to either the drainage system or the root media into open and closed systems: where the excess nutrient solution is circulated continuously (Jensen, 1999).

Fusarium oxysporum f. sp. radicis-lycopersici, the causal agent of Fusarium crown and root rot (FCRR) of tomato (Lycopersicon esculentum Mill.) is an important disease worldwide and is responsible for yield losses in fields and commercial greenhouses. Recently, FCRR was effectively managed by application of the fungicides metam sodium (MC Govern et al., 1993) and benomyl. However, repeated application of such broad-spectrum fungicides might cause environmental problems and the appearance of fungicide-resistant strains of Fusarium. Thus, alternative control measures are needed as soon as possible (Hassanein, 2010).

Biological control has the potential to manage FCRR and wilt. Among antagonists that have shown satisfactory degrees of control against this disease, Trichoderma spp. (Muslim et al., 2003 and Hassanein, 2010), Bacillus subtilis, Bacillus polymyxa and Paenibacillus polymyxa (Pandey and Pandey, 2005, Han et al., 2005 and Xueli et al., 2008).

It is interest in this research to evaluate the efficacy of Bacillus subtilis, $B$. polymyxa and Trichoderma harzianum on suppression of Fusarium oxysporum growth in vitro and to test the efficacy of these biocontrol agents to control wilt as well as crown and root rot of hydroponically grown tomato and to evaluate the effect of these PSMs on tomato growth and yield by using seeds and seedlings treatments.

\section{Materials and Methods}

Experimental conditions and plant material:

The study was conducted at the experimental site of Central Laboratory for Agricultural Climate (CLAC), Agricultural Research Centre (ARC), Dokki, Giza governorate, in a plastic house, under soilless conditions, during the season of 2007 / Egypt. J. Phytopathol., Vol. 39, No. 1 (2011) 
2008. Tomato seeds and seedlings (Lycopersicon esculentum, Mill.) cv. Castle Rock, were obtained from ARC.

Microbial inoculants:

The phytopathogenic strain of Fusarium oxysporum f. sp. radicis lycopersici (FORL) EMCC632, and the biocontrol agents, Trichoderma harzianum (TH) EMCCS40, Bacillus subtilis (BS) and Bacillus polymyxa (BP) were obtained from Microbiological Resources Center (MIRCEN), Faculty of Agriculture, Ain Shams University.

Soilless culture system:

Plastic pots ( $25 \mathrm{~cm}$ in diameter) were sterilized for 15 minutes by soaking them in $5 \%$ formalin solution and left for several days until formalin odor disappeared, two sets of pots were filled with a substrate mixture of perlite and peat-moss (1:1 $\mathrm{v} / \mathrm{v}$ ) and autoclaved for 20 minutes at $121^{\circ} \mathrm{C}$. The physical properties of perlite and peat - moss were illustrated in tables (1) and (2) respectively.

Table (1): Physical properties of perlite

\begin{tabular}{|l|c|}
\hline \multicolumn{1}{|c|}{ Particle size } & $0.5 \mathrm{~mm}$ \\
\hline Bulk density & 89.2 \\
\hline \% Pore space & 90.1 \\
\hline \% Air space & 32.0 \\
\hline \% Easily available water & 24.6 \\
\hline
\end{tabular}

Table (2): Physical properties of peat-moss

\begin{tabular}{|l|c|}
\hline \multicolumn{1}{|c|}{ Apparent density $\mathrm{gm} / \mathrm{cm}^{3}$} & 0.07 \\
\hline \% Total pore space & 94.3 \\
\hline \% Air content & 32.6 \\
\hline \% Easily available water & 26 \\
\hline \% Buffering capacity & 6.2 \\
\hline \% Non-available water & 28.9 \\
\hline
\end{tabular}

Nutrient solution:

The used nutrient solution was adapted from Cooper solution depending on the analysis of the local water as described by El-Behairy (1994). Concentrations of elements in the nutrient solution are illustrated in Table (3). The nutrient solution contained $75 \%$ of the recommended dose of mineral nitrogen and desired initial concentration of the nutrient solution was maintained by adding tap water to the stock solutions. The solution volume was adjusted twice a week. Electrical conductivity (EC) was maintained between $2.0-2.5 \mathrm{~m} \cdot \mathrm{mhos}^{-1}$ and $\mathrm{pH}$ was maintained between 5.5 - 6.5 throughout the experimental time. Digital EC meter was used to adjust the EC to the required level. The irrigation system was connected to a digital timer in order to circulate the nutrient solution for 15 minutes every 2 hours during daytime and for 15 minutes 2 times during night.

Egypt. J. Phytopathol., Vol. 39, No. 1 (2011) 
Table (3): Composition of the nutrient solution

\begin{tabular}{|l|c|}
\hline \multicolumn{1}{|c|}{ Element } & Concentration $(\mathrm{ppm})$ \\
\hline Nitrogen & 250 \\
\hline Phosphorus & 35 \\
\hline Potassium & 350 \\
\hline Calcium & 180 \\
\hline Magnesium & 50 \\
\hline Iron & 3 \\
\hline Manganese & 1 \\
\hline Copper & 0.1 \\
\hline Zinc & 0.06 \\
\hline Boron & 0.1 \\
\hline Molybdenum & 0.01 \\
\hline
\end{tabular}

Antagonistic test:

Nutrient agar plates were streaked with $B$. subtilis and B. polymyxa and incubated at $37^{\circ} \mathrm{C}$ for 24 hours, then inoculated with a disc of $F$. oxysporum and incubated at $25^{\circ} \mathrm{C}$ for 3 days. PDA plates were streaked with $T$. harzianum and incubated at $25^{\circ} \mathrm{C}$ for 2 days, then inoculated with a disc of $F$. oxysporum and incubated for 3 days at $25^{\circ} \mathrm{C}$. The level of inhibition was determined as described by Yuan and Crawford (1995). Briefly, the level of inhibition was defined as the subtraction of the pathogen's growth radius $\left\{\gamma_{0}\right.$ (in $\left.\left.\mathrm{cm}\right)\right\}$ of a control culture from the pathogen's growth radius in the direction of antagonistic fungus colony $\{\gamma($ in $\mathrm{cm})\}$,

$$
\text { where } \Delta \gamma=\gamma_{0}-\gamma \text {. }
$$

Inhibition was indicated when mycelial growth of pathogens in the direction of fungi colony was retarded.

\section{Greenhouse tests:}

Inoculum preparation of the pathogen:

A spore suspension $\left(10^{7}\right.$ conidia + mycelial fragments $\left./ \mathrm{ml}\right)$ was prepared by blending 14-days old cultures of $F$. oxysporum grown on PDA at $25^{\circ} \mathrm{C}$ with sterile distilled water and filtering the suspension through cheesecloth. Conidial densities in the suspension were determined by use of a hemocytometer under a light microscope (Ozbay et al., 2004).

\section{Pathogenicity test:}

Pathogenicity test was conducted under greenhouse conditions using the previously prepared pathogen inoculum. Pots $(25 \mathrm{~cm}$ diameter $)$ were sterilized by immersing in 5\% formalin for 15 minutes, then left to dry for 10 days. Pots were then filled with the sterilized substrate which is a mixture of perlite and peat-moss $(1: 1 \mathrm{v} / \mathrm{v})$. Three sets of pots were prepared, the first two sets were infested with the pathogen inoculum and the third one contains non infested sterilized substrate (autoclaved for 20 minutes at $121^{\circ} \mathrm{C}$ ) to serve as control. In the first set, ten tomato seeds were surface sterilized with $70 \%$ ethanol for $2 \mathrm{~min}$. then in $1 \%$ sodium Egypt. J. Phytopathol., Vol. 39, No. 1 (2011) 
hypochlorite for 30 seconds then washed several times with sterile water. Seeds were sown at $3 \mathrm{~cm}$ depth and when emergence was completed, the seedlings density was reduced to five seedlings per pot. In the second set, 5 seedlings (two weeks age) were planted. Pots were kept in the greenhouse and watered every other day with equal amounts of water. The growing seedlings were observed daily for one month and disease incidence was evaluated for severity of damping-off and foliar symptoms four weeks after inoculation (Leath et al., 1989).

Substrate infestation and greenhouse preparations for application of biocontrol agents:

Two sets of pots were filled with the sterile substrate. In the first set of pots, surface sterilized seeds were divided into 3 parts, the first part was soaked in a cell suspension of B. subtilis $\left(10^{7}\right.$ spores $\left./ \mathrm{ml}\right)$, the second part was soaked in a cell suspension of Bacillus polymyxa $\left(10^{7}\right.$ spores $\left./ \mathrm{ml}\right)$ and the third part was soaked in a spore suspension of $T$. harzianum $\left(10^{7}\right.$ conidia $\left./ \mathrm{ml}\right)$. In the second set of pots, the roots of five tomato seedlings (two weeks age) were soaked in the spore suspension of the previous antagonists and transplanted in each pot. Pathogen inoculum was added during the sowing of the seeds and seedlings.

Pots were fertilized weekly with the nutrient solution and watered every other day with equal amounts of water. Each set of pots contains the substrate with five treatments:

(i). Sterilized non-infested substrate (-ve control).

(ii). Substrate $+F$. oxysporum (+ve control).

(iii). $\quad$ " $\quad$ F. oxysporum + B. subtilis.

(iv). $\quad$ " F. oxysporum + B. polymyxa.

(v). $\quad$ " $\quad$ F. oxysporum + T. harzianum.

Each treatment was replicated three times. In case of seeds treatment, the growing tomato seedlings were examined to determine the percentages of pre- and post- emergence damping-off. The percentage of pre-emergence damping-off was determined after 15 days from sowing as:

$$
\% \text { Pre-emergence damping-off }=\frac{\text { No. of ungerminated seeds } / \text { pot }}{\text { No. of sown seeds } / \text { pot }} \times 100
$$

The percentage of post-emergence damping-off was determined after 45 days from sowing as:

$$
\% \text { Post-emergence damping-off }=\frac{\text { No. of died seedlings } / \text { pot }}{\text { No. of sown seeds } / \text { pot }} \times 100
$$

Nine weeks after sowing, the growing tomato plants were examined to determine the percentage of disease incidence and percentage of disease control comparing with the control plants. The following formula was used in calculations:

$$
\begin{gathered}
\% \text { Disease incidence }=\frac{\text { No. of infected plants }}{\text { Total No. of plants }} \times 100 \\
\% \text { Disease control }=100-\text { disease incidence. }
\end{gathered}
$$

Egypt. J. Phytopathol., Vol. 39, No. 1 (2011) 
Measurement of some plant growth parameters:

At the end of growth season, the whole plants were carefully removed and washed to remove any substrate particles from shoot and root systems. Growth criteria measured were number of leaves, shoot height, root length, fresh and dry weights of shoot and root.

Statistical analysis:

The collected data were analyzed using ANOVA statistical analysis (Snedecor and Cochran, 1980). The least significant difference (L.S.D) was used to compare between the means.

\section{Results}

In vitro antagonistic activity of $B$. subtilis, B. polymyxa and $T$. harzianum against $F$. oxysporum:

B. subtilis, B. polymyxa and T. harzianum showed antagonistic activities of varying degrees against F. oxysporum as shown in Table (4). T. harzianum was the most potent antagonistic agent and causes a percentage of inhibition of $62 \%$, followed by B. subtilis (32.4\%) and finally B. polymyxa (Table 4 and Fig.1).

Table (4): In vitro antagonistic activity of the tested biocontrol agents against F. oxysporum.

\begin{tabular}{|c|c|c|c|c|}
\hline \multirow{2}{*}{ Antagonist } & \multicolumn{4}{|c|}{ F. oxysporum } \\
\cline { 2 - 5 } & $\gamma_{\mathrm{o}}$ & $\Gamma$ & $\Delta \gamma$ & \% inhibition \\
\hline B. subtilis & 3.7 & 2.5 & 1.2 & 32.4 \\
\hline B. polymyxa & 3.7 & 3.0 & 0.7 & 18.9 \\
\hline T. harzianum & 3.7 & 1.4 & 2.3 & 62.0 \\
\hline
\end{tabular}

$\%$ inhibition $=\left(\Delta \gamma / \gamma_{0}\right)$.

\section{Where:}

$\gamma_{\mathrm{o}}$ : Pathogen growth radius of a control culture $(\mathrm{cm})$.

$\gamma$ : Pathogen growth radius in direction of the antagonist $(\mathrm{cm})$.

$\Delta \gamma=\gamma_{\mathrm{o}}-\gamma$

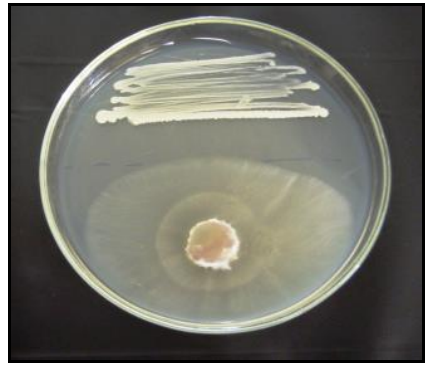

(A)

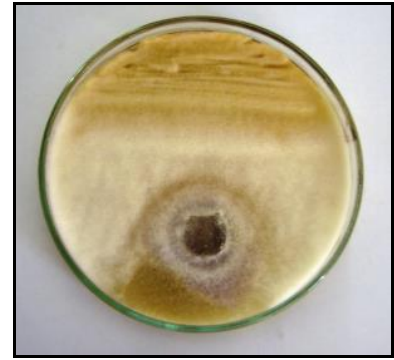

(B)

Fig. (1): In vitro antagonistic activity of the tested PSM $_{\mathrm{s}}$ against $F$. oxysporum, (A): B. subtilis, and (B): T. harzianum.

Egypt. J. Phytopathol., Vol. 39, No. 1 (2011) 


\section{Greenhouse tests:}

Effect of PSMs on pre- and post- emergence damping-off of tomato plants:

Table (5) showed that the highest percentage of pre- emergence damping- off was recorded with $F$. oxysporum +ve control $(73 \%)$ and the lowest one was observed with T. harzianum (50\%) followed by B. subtilis $(57 \%)$. Also, the + ve control gave the highest post- emergence damping- off value $(23 \%)$ followed by $T$. harzianum $(10 \%)$ while the -ve control gave the lowest post- emergence dampingoff value $(0 \%)$.

Table (5): Effect of $\mathrm{PSM}_{\mathrm{s}}$ on pre- and post- emergence damping-off of tomato plants

\begin{tabular}{|c|c|c|}
\hline \multirow{2}{*}{ Treatment } & \multicolumn{2}{|c|}{ \% damping - off } \\
\cline { 2 - 3 } & Pre-emergence & Post-emergence \\
\hline Sterilized substrate (- ve control) & 60 & 0 \\
\hline Substrate + F. oxysporum $(+$ ve control) & 73 & 23 \\
\hline Substrate $+F$. oxysporum + B. subtilis & 57 & 7 \\
\hline Substrate $+F$. oxysporum + B. polymyxa & 63 & 3 \\
\hline Substrate $+F$. oxysporum + T. harzianum & 50 & 10 \\
\hline
\end{tabular}

Pathogenicity tests in vivo using seeds and seedlings inoculation:

Soaking surface sterilized tomato seeds, in $F$. oxysporum spore suspension (+ ve control) showed the identical symptoms of Fusarium root rot disease of tomato. Also, the pathogen was capable to produce severe reduction in root growth with brown discoloration (Fig. $2 \mathrm{~B}$ - ii) and cause a disease incidence on tomato in infested substrate with a value of $25 \%$ (Table 6).

Similarly, tomato seedlings grown in substrate infested with $F$. oxysporum showed the same symptoms of root system (Fig. 3 B - ii). The percentage of disease incidence was $66.6 \%$ (Table 6). So, results showed that the pathogenicity of $F$. oxysporum in case of seeds inoculation was less $(25 \%)$ than that in case of seedlings.

Effect of PSM $M_{s}$ on percentages of disease incidence and disease control of inoculated seeds and seedlings:

Table (6) shows the effect of $\mathrm{PSM}_{\mathrm{s}}$ on percentages of disease incidence and disease control of Fusarium root rot using seeds and seedlings inoculation. In case of seeds inoculation, when substrate infested with $F$. oxysporum without $\mathrm{PSM}_{\mathrm{s}}$ inoculation, there was a disease incidence with a value of $25 \%$ while in case of seedlings inoculation, it was $66.6 \%$ and the disease control percentages were $75 \%$ and $33.3 \%$, respectively. This means that seedlings were more susceptible to infection by $F$. oxysporum than seeds. Substrate inoculation with $T$. harzianum gave the highest disease control percentage $(93 \%)$ in case of seeds inoculation while in case of seedling inoculation B. subtilis gave the highest one $(73.3 \%)$. 


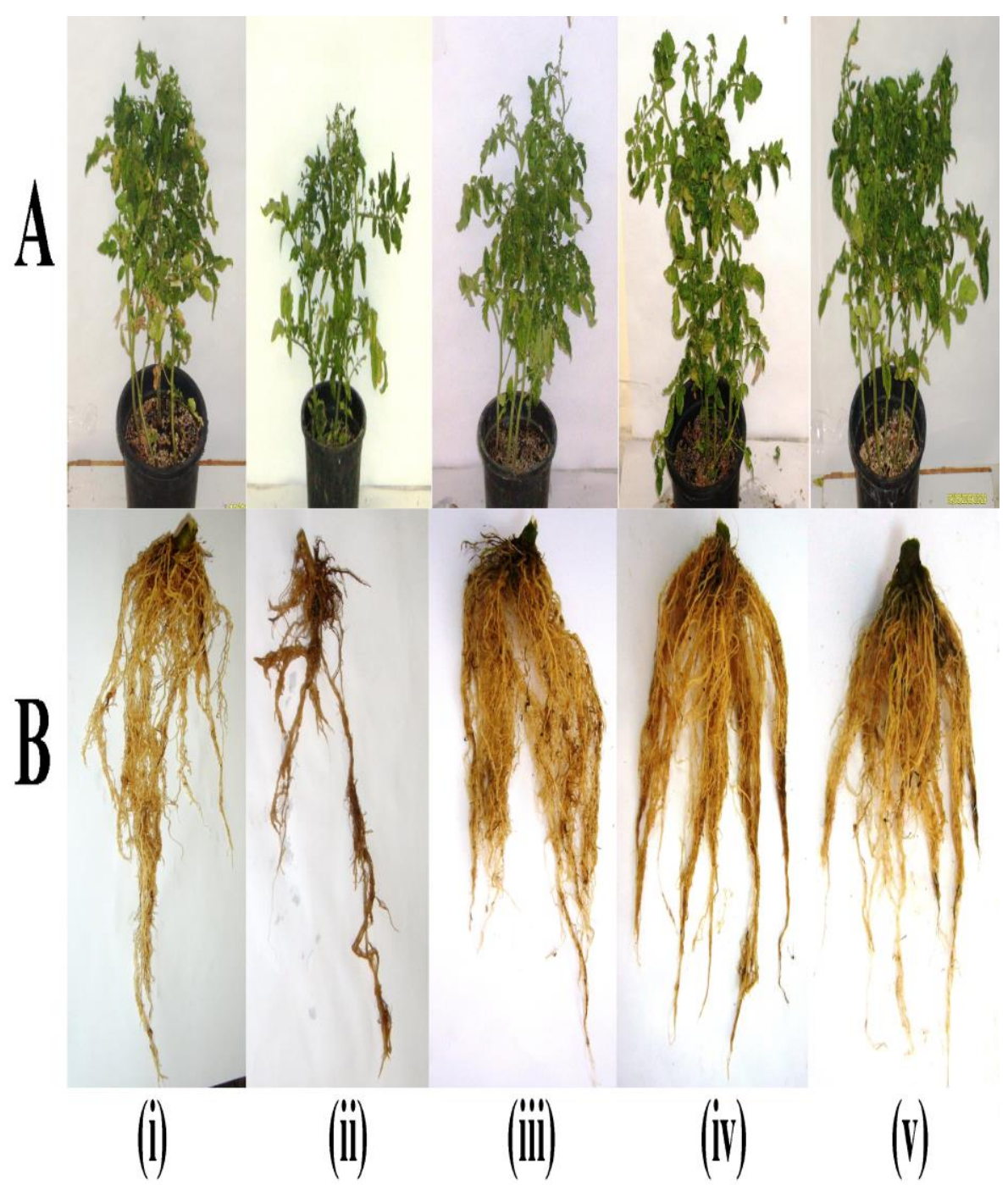

Fig (2): Pathogenicity test showing treatment of tomato seeds with $B$. subtilis, $B$. polymyxa and $T$. harzianum against $F$. oxysporum (A: shoot system and $B$ : root system).

\section{Where:}

(i): Sterilized non - infested substrate + non - inoculated seeds (-ve control).

(ii): Substrate $+F$. oxysporum + non-inoculated seeds.

(iii): Substrate $+F$. oxysporum + seeds soaked in $B$. subtilis.

(iv): Substrate $+F$. oxysporum + seeds soaked in B. polymyxa.

(v): Substrate $+F$. oxysporum + seeds soaked in $T$. harzianum. 


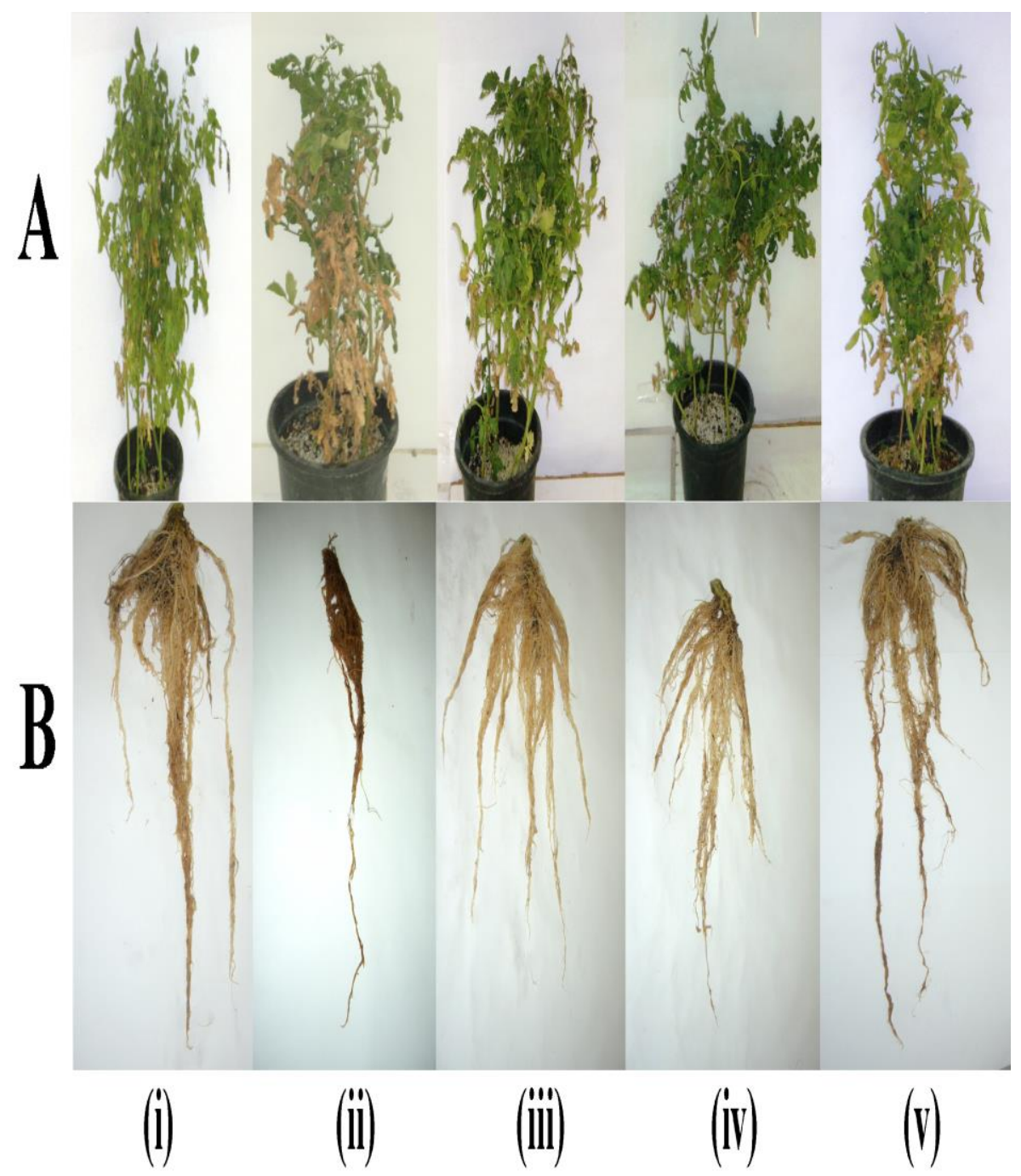

Fig (3): Pathogenicity test showing treatment of tomato seedlings with $B$. subtilis, B. polymyxa and $T$. harzianum against $F$. oxysporum (A: shoot system and $B$ : root system).

\section{Where:}

(i): Sterilized non - infested substrate + non - inoculated seedlings.

(ii): Substrate $+F$. oxysporum + non-inoculated seedlings.

(iii): Substrate $+F$. oxysporum + seedlings inoculated with $B$. subtilis.

(iv): Substrate $+F$. oxysporum + seedlings inoculated with $B$. polymyxa.

(v): Substrate $+F$. oxysporum + seedlings inoculated with $T$. harzianum . 
Table (6): Effect of PSMs on percentages of disease incidence and disease control of inoculated seeds and seedlings

\begin{tabular}{|c|c|c|c|c|}
\hline \multirow{2}{*}{ Treatment } & \multicolumn{2}{|c|}{ Seeds } & \multicolumn{2}{c|}{ Seedlings } \\
\cline { 2 - 5 } & $\begin{array}{c}\text { \% Disease } \\
\text { incidence }\end{array}$ & $\begin{array}{c}\text { \% Disease } \\
\text { control }\end{array}$ & $\begin{array}{c}\text { \% Disease } \\
\text { incidence }\end{array}$ & $\begin{array}{c}\text { \% Disease } \\
\text { control }\end{array}$ \\
\hline $\begin{array}{c}\text { Sterilized substrate } \\
\text { (-ve control) }\end{array}$ & 0.0 & 0.0 & 0.0 & 0.0 \\
\hline $\begin{array}{c}\text { Substrate }+ \text { F. } \text { oxysporum } \\
\text { (+ ve control) }\end{array}$ & 25.0 & 75.0 & 66.6 & 33.3 \\
\hline $\begin{array}{c}\text { Substrate }+ \text { F. oxysporum }+ \\
\text { B. subtilis }\end{array}$ & 9.0 & 91.0 & 26.6 & 73.3 \\
\hline $\begin{array}{c}\text { Substrate }+ \text { F. oxysporum }+ \\
\text { B. polymyxa }\end{array}$ & 10.0 & 90.0 & 46.6 & 53.3 \\
\hline $\begin{array}{c}\text { Substrate + F. oxysporum }+ \\
\text { T. harzianum }\end{array}$ & 7.0 & 93.0 & 53.3 & 46.7 \\
\hline
\end{tabular}

Effect of $\mathrm{PSM}_{s}$ on some growth parameters of tomato plants against F. oxysporum (seeds and seedlings inoculation):

Results in Table (7) showed that the PSM ${ }_{\mathrm{s}}$ were able to induce the improvement of some growth parameters as number of leaves, shoot height, root length, fresh and dry weights of shoots and roots with seeds and seedlings inoculation. Concerning seeds inoculation, Table 7 show that substrate infested with $F$. oxysporum and inoculated with $B$. subtilis gave the highest values of number of leaves, shoot height, root length, fresh and dry weights of roots. While seeds inoculated with $B$. polymyxa and grown in substrate infested with $F$. oxysporum gave the highest values of fresh weight and dry weights of shoots and roots.

In case of seedlings inoculation, results in Table (7) show that seedlings transplanted in substrate infested with $F$. oxysporum and inoculated with $B$. subtilis gave the highest values of number of leaves, shoot height, root length, fresh and dry weights of shoots. While seedlings transplanted in substrate infested with $F$. oxysporum and inoculated with $B$. polymyxa gave the highest values of fresh and dry weights of roots.

\section{Discussion}

Recently, interest in biological control of plant pathogens has increased, in order to find alternatives to the use of chemicals for disease control. Several authors are focused on the potential role of rhizosphere microorganisms in reducing incidence of infection in many vegetable crops. (Gupta et al., 2000; El-Mehalawy et al., 2004; Hassanein, 2010 and Hassanein et al., 2010).

Many proposals explained the possible mode of action of rhizospheric microorganisms in reducing disease incidence including: inhibition of the pathogen by antimicrobial compounds (antibiosis); competition for colonizing sites and nutrients supplied by seeds and roots, induction of plant resistant mechanisms;

Egypt. J. Phytopathol., Vol. 39, No. 1 (2011) 
inactivation of pathogen germination factors presented in seed or root exudates; degradation of pathogenicity factors such as toxins; and parasitism that might involve production of extracellular cell wall degrading enzymes, for example, chitinase and $\beta-1,3$ glucanase that lyses pathogen cell wall. These modes of action have been studied by many workers (Whipps and Lumesden, 2001).

Wilt of tomato caused by Fusarium oxysporum is a disease of economic significance since it causes a great loss in the total production of this important vegetable crop. The pathogen infects plant through root and hypocotyl wounds causing chlorosis, senescence, and discoloration of the vascular system of root, stem and petioles. Possibilities to manage Fusarium wilt of tomato by using fungicides or resistant cultivars are limited. Therefore, other strategies to control this disease such as biological control are being developed (Attia and Hamed, 2005; Borrero et al., 2005; Hassanein, 2010 and Hassanein et al., 2010).

So, we are focusing in this study on the role of the selected rhizosphere microorganisms which are useful as bio-control agents against plant pathogens, for their potent antagonistic activity, in addition to their ability to produce antifungal substances which are capable to inhibit fungal infection. We have to consider, the ability of these microorganisms in producing plant growth promoting substances which improve plant production.

From the possible mechanisms for increasing plant growth, production of secondary metabolites such as antibiotics, cyanide and hormone-like substances, production of siderophores, production of plant growth regulators and phosphate solubilization. The plant growth-regulating substances are naturally occurring organic compounds that influence physiological processes in plants (El-Mehalawy et al., 2004). When these plant growth regulators produced endogenously in plants, they were referred to as "plant hormones" or "phytohormones", while when produced exogenously by rhizosphere microbiota, they were termed "plant growth regulators".

Another mechanism of growth promotion is the increasing of mobilization of insoluble nutrients and subsequent enhanced plant nutrients uptake (Lifshitz et al., 1987). Also, increasing the iron availability in the rhizosphere by producing siderophores (Kloepper et al., 1980) and the production of plant growth regulators (Dubeikovsky et al., 1993).

The antagonism between rhizosphere microorganisms is associated with the production of water-soluble antifungal metabolites which diffused into the medium and inhibited the fungal growth (Crawford et al., 1993) and when rhizosphere microorganisms are used as bio-control agents against $F$. oxysporum in the greenhouse experiments, they improved external morphological features of the plants (Hassanein, 2010). Rhizosphere microorganisms were also produced IAA or IAA analogue, siderophores, and solubilized phosphate in soil. This effect confirms their role in promoting plant growth and suppressing plant diseases incidence (Dubeikovsky et al., 1993). 
In this study, the tested microorganisms were found to be effective in reducing the percentage of disease incidence. Phytostimulating microorganisms $\left(\mathrm{PSM}_{\mathrm{s}}\right)$ such as B. subtilis, B. polymyxa and T. harzianum increased shoot and root growth and total plant biomass. This might be due to the growth promoting ability of PSM $\mathrm{s}$ which was demonstrated earlier in several crops (Attia et al., 2004). Disease reduction by $\mathrm{PSM}_{\mathrm{s}}$ was due to the higher antagonistic potential of $\mathrm{PSM}_{\mathrm{S}}$ by different means such as antibiosis, parasitism, production of lytic enzymes, etc. Thus, the bioprotection exerted by PSM $_{\mathrm{s}}$ appears to be the result of a combination of local and systemic mechanisms. The same conclusion was reached by immunocytochemical studies (Cordier et al., 1998).

The results of this study revealed that B. subtilis and B. polymyxa showed variable degrees of antagonistic activities against $F$. oxysporum. This might be due to their antibiosis towards the pathogenic fungi due to the production of antagonistic compounds like siderophores which affect the respiratory system of the pathogenic fungi and results in their growth inhibition (Kirimura et al., 1987) or production of antibiotics (Hebbar et al., 1992). Farahat (1998) stated that B. subtilis produces bacterocin and subtilin antibiotics.

Also, B. subtilis showed considerable effect in controlling Fusarium wilt disease. This might be due to that, this bacterium produces more antibiotics (bacteriocin and subtilin) which act as inhibitors to pathogenic fungi (Farahat, 1998). In addition to this action, $B$. subtilis also grows very fast and occupies the court of infection and consumes all available nutrients. This action prevents pathogen spores to reach susceptible tissues (Wolk and Sorkar, 1994). While T. harzianum is characterized by its potent and remarkable antagonistic activity, this might be due to its ability for producing an array of metabolites which have antifungal activity. This finding runs parallel with that reported by Gupta et al. (2000).

Inoculation of plants with $T$. harzianum induced chitinase activities in both leaves and roots of cucumber seedlings. These proteins facilitate Trichoderma penetration of the host components for nutrition (Yedida et al., 1999 and Bolar et al., 2000).

Results also showed that all antagonists significantly reduced the percentage of disease incidence or disease severity and increased tomato vegetative growth compared with control treatments. This might be due to that, all used antagonists have different effects against the pathogenic fungus. This effect might be also due to direct mycoparasitism as in $T$. harzianum as previously mentioned or due to secretion of enzyme and / or antifungal substances (Padares et al., 1992) or also stimulate resistance in the host (Howell et al., 2000 and Bolar et al., 2000).

The ability of microorganisms to produce antibiotics depends not only on the genome of the organism but also on the physical and chemical environment which determines the extent to which the genetic information is expressed and changes in the environment alter this expression (Aharonowitz and Demain, 1979).

The reduced incidence of Fusarium wilt disease caused by the addition of rhizosphere bio-control agents might be also due to the incubation period in the Egypt. J. Phytopathol., Vol. 39, No. 1 (2011) 
substrate which aid in the establishment of the introduced microorganisms and enables them to multiply in the substrate or to activate the mechanisms of antagonism. This finding is similar to that reported by Hassanein (2010).

Various studies indicated that increased resistance of the plants might be associated in part with marked metabolic changes in host, including accumulations of hydrolases such as chitinases and B-1,3- glucanase with antimicrobial potential, and deposition of structural polymers such as lignin and hydroxyproline- rich glycoproteins, which might be important in the resistance process (Yedida et al., 1999).

The increased accumulation of chitinase and B-1, 3-glucanase due to the application of bio-control agents, in addition to hydrolyzing chitin and $\beta$-1, 3-glucan respectively which are the major components of the fungal cell walls, might have also released elicitors from the walls of fungi which in turn might have triggered various defense related activities in tomato (Ren and West, 1992).

\section{Conclusion}

The biological agents in order to reach a stage of commercial utilization for disease control this require extensive research and technology development. All other methods, such as fungicides, which are used to control disease incidence are time consuming, uneconomical, pollute the atmosphere and harmful to the environment. Also, the repeated use of these chemicals increased the organism resistance against them.

\section{References}

Aharonowitz, Y. and Demain, A.L. 1979. Nitrogen nutrition and regulation of cephalosporin production in Streptomyces clavuligerus. Can. J. Microbiol., 25: 61-67.

Attia, M. and Hamed, A. 2005. Induction of defense responses in tomato plants inoculated with phytostimulation microorganisms against Fusarium oxysporum. Arab Universities, Journal of Agricultural Science., 13(3): 689-705.

Attia, M.; Hamed, H.A. and Turky, A.S. 2004. Influence of root colonization with Bacillus subtilis, Trichoderma harzianum and arbuscular mycorrhizae on promoting tomato seedling, yield and protection against Fusarium crown and root rot. Bull. NRC, Egypt, 29: 347-360.

Baudoin, W.O.; Winsor, G.W. and Schwarz, M. 1990. Soilless culture for horticulture crop production. Food and agriculture organization of the united nation Roma (FAO). Lands man's books hop ltd Buckenttil; Bromyard and Herefords. Technical paper: pp 188.

Bolar, J.P.; Norelli, J.L.; Wong, K.W.; Hayes, C.K.; Harman, Q.E. and Aldwinckle, H.S. 2000. Expression of Endochitinase from Trichoderma harzianum in transgenic apple increases resistance to apple scab and reduces vigour. Phytopathology, 90: 72-77. 
Borrero, C.; Trillas, M. I.; Ordovàs, J.; Tello, J. C. and Avilés, M. 2004. Predictive factors for the suppression of Fusarium wilt of tomato in plant growth media. Phytopathology, 94: 1094-1101.

Borrero, C.; Infantes, M.J.; Gonzalez, E.; Aviles, M. and Tello, J.C. 2005. Relation between suppressiveness to tomato Fusarium wilt and microbial populations in different growth media. Acta-Horticulture, 697: 425-430.

Cordier, C.; Pozo, M.J.; Barea, J.M.; Gianinazzi, S. and Gianinazzi-Pearson, V. 1998. Cell defense responses associated with localized and systemic resistance to Phytophthora induced in tomato by an arbuscular mycorrhizal fungus. Molecular Plant Microbe-Interactions, 11: 1017-1028.

Crawford, D.L.; Lynch, J.M.; Whipps, J.M. and Ously, M.A. 1993. Isolation and characterization of actinomycete antagonists of a fungal root pathogens. Applied and Environmental Microbiology, 59: 3899-3905.

Dubeikovsky, A.N.; Mordukhova, E.A.; Kochetkov, V.V.; Polikarpova, F.Y. and Boronin, A.M. 1993. Growth promotion of blackcurrant softwood cuttings by recombinant strain Pseudomonas fluorescence BSP53a synthesizing and increased amount of Indol-3-acetic acid. Soil Biol. Biochem., 25: 1277-1281.

El-Behairy, U.A. 1994. The effect of levels of phosphorus and zinc in the nutrient solution on macro and micronutrients uptake and translocation in cucumber (Cucumus sativus L.) grown by the nutrient film technique. Ph.D. thesis, London University pp 299.

El-Mehalawy, A.A.; Hassanein, N.M.; Karam El-Dein, Z.A.; Khater, H.M. and Yousef, A.Y. 2004. Influence of maize root colonization by the rhizosphere actinomycetes and yeast fungi on plant growth and on the biological control of late wilt disease. In. J. Agric \& Biol., 6(4): 599-605.

Farahat, A. 1998. Biological control of some potato bacterial diseases. Ph.D. Thesis, Fac. Agric., Menoufia Univ., pp 118.

Gupta, V.P.; Bochow, H.; Dole, S. and Fischer, I. 2000. Plant growth-promoting Bacillus subtilis as potential inducer of systemic resistance in tomato against Fusarium wilt. Zeitschrift-fur-pflanzenkrankheiten-und-pflanzenschutz, 107(2): 1445-154.

Han, J.S.; Cheng, J.H.; Yoon, T.M.; Song, J.; Rajkarnikar, A.; Kim, W.G.; Yoo, I.D.; Yang, Y.Y. and Suh, J.W. 2005. "Biological control agent of common scab disease antagonistic strain Bacillus sp. sunhua". J. Appl. Microbiol., 99: 213221.

Hassanein, N.M. 2010. The role of biotic and abiotic agents in the control of damping - off and wilt of bean plants. Egypt. J. Exp. Biol. (Bot.), 6(1): 21-31.

Hassanein, N.M; Abou-Zeid, M.A.; Youssef, K.A. and Mahmoud, D.A. 2010. Control of tomato early blight and wilt using aqueous extract of neem leaves. Phytopathol. Mediterr., 49: 143-151.

Egypt. J. Phytopathol., Vol. 39, No. 1 (2011) 
Hebbar, K.P.; Davey, A.G. and Dart, P.J. 1992. Rhizobacteria of maize antagonistic to Fusarium moniliforme, a soil-borne fungal pathogen: colonization of rhizosphere and roots. Soil Biol. Biochem., 24: 989 -997.

Howell, C.R.; Hanson, L.E.; Stipanovic, R.D. and Puckhaber, I. 2000. Induction of terpenoid synthesis in cotton roots and control of Rhizoctonia solani by seed treatment with Trichoderma virens. Phytopathology, 90: 248-252.

Hunger, B.C. 1979. Hydroponic fundamentals. In Commercial applications of hydroponics'. Agriculture Note Series No. 12, Dept. of Agriculture, Victoria, England. Paper No. 1, 4 pp.

Jensen, M.H. 1999. Hydroponic worldwide. Acta Hort., 48: 719-729.

Kirimura, K.; Hiowatari, Y. and Usami, S. 1987. Alternations of respiratory system in Aspergillus niger under the conditions of citric acid fermentation. Agric. Biol. Chem., 51: 1299-1303.

Kloepper, J.W.; Schroth, M.N. and Miller, T.D. 1980. Effects of rhizosphere colonization by plant growth promoting rhizobacteria on potato plant development and yield. Phytopathology, 70: 1078-1082.

Leath, K.T.; Lukezic, F.L.; Pennypacker, B.W.; Kindall, W.A.; Lovine, R.G. and Hill, R.R. 1989. Interaction of Fusarium avenaceum and Pseudomonas viridiflava in root rot of red clover. Phytopathology, 79: 436-440.

Lifshitz, R.; Kloepper, J.W. and Kozlowski, M. 1987. Growth promotion of canola (rapeseed) seedlings by a strain of Pseudomonas putida under gnotobiotic conditions. Can. J. Microbiol., 33: 390-395.

McGovern, R.J.; Datnoff, L.E. and Vavrina, C.S. 1993. Evaluation of seven tomato genotypes for resistance to Fusarium oxysporum f. sp. radicis-lycopersici. Phytopathology, 83: 1395.

Muslim, A.; Horinouchi, H. and Hyakumachi, M. 2003. Control of Fusarium crown and root rot of tomato with hypoviulent binucleate Rhizoctonia in soil and rock wool systems. Plant Dis., 87: 739-747.

Ozbay, N.; Newman, S.E. and Brown, W.M. 2004. Evaluation of Trichoderma harzianum strains to control crown and root rot of greenhouse fresh market tomatoes. Acta Hort., 635, ISHS.

Padares, D.F.; Hockenhull, J.; Jensen, D.f. and Mathur, S.B. 1992. In vivo screening of Trichoderma isolates for antagonism against Sclerotium rolfsii using rice seedlings. Bulletin Oil B/SROOP, 15(1): 33-35.

Pandey, K.K. and Pandey, P.K. 2005. Differential response of biocontrol agents against soil pathogens on tomato, chilli and brinjal. Indian Phytopath., 58(3): 329-331.

Ren, Y.Y. and West, C.A. 1992. Elicitation of diterpene biosynthesis in rice (Oryzae sativa L.) by chitin. Plant Physiol., 99: 1169-1178.

Egypt. J. Phytopathol., Vol. 39, No. 1 (2011) 
Snedecor, R. G. and Cochran, W. G. 1980. Statistical methods. Sixth edition, Iowa State Univ. Press, Amer. Iowa, USA.

Trillas, I.; Avilés, M.; Ordovás, J.; Bello, A. and Tello, J.C. 2002. Using compost as a methyl bromide alternative. Biocycle, 43: 64-68.

Weller, D.M.; Raaijmkers, J.M.; McSpadden, G.; Gardener, B.B. and Thomashow, L.S. 2002. Microbial populations responsible for specific soil suppressiveness to plant pathogens. Annul. Rev. Phytopathol., 40: 309-348.

Whipps, J.M. and Lumsden, R.D. 2001. Commercial use of fungi as plant disease biological control agents: status and prospects. In: Fungal biocontrol agentsprogress, problems and potential (Butt, T.; Jackson, C.; and Maga, N. eds.). Walling: CAB International.

Wolk, M. and Sorkar, S. 1994. Antagonism in vivo of Bacillus spp. Against Rhizoctonia solani and Pythium spp. Anzeiger fur schadling skundey pflanzenschutz; Umweltschutz, 67(1): 1-5.

Xueli, C.; Guang Hua, W.; Jian, J. and Baolin, L. 2008. Biocontrol effect of Paenibacillus polymyxa BRF-1 and Bacillus subtilis BRF-2 on Fusarium wilt disease of cucumber and tomato. Chinese Journal of Eco Agriculture., 16(2): 446-450.

Yedidia, I.; Benhamou, N. and Chet, I. 1999. Induction of defense responses in cucumber plants (Cucumis sativus L.) by the biocontrol agent Trichoderma harzianum. Appl. Environ. Microbiol., 65(3): 1061-1070.

Yuan, W.M. and Crawford, D.L. 1995. Characterization of Streptomyces lydicus WYEC-180 as a potential biocontrol agent against fungal root and seed rots. Appl. Environ. Microbial., 61(8): 3119-3128.

Corresponding author: Hassanein, N.M.

E-mail: naziha_hassanein@sci.asu.edu.eg 
تقليل القدرة الإمراضية لفطر فيوزاريم أوكسيسبورم المستحثة

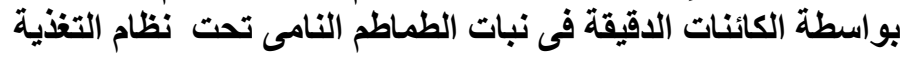

المائي نزيهة حسنين1 ، مصطفي حمدي قطان2 ، اسامة احمد علي البحيري3 ،و دينا عادل شفيق هنبن

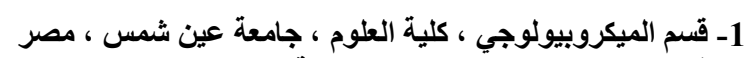

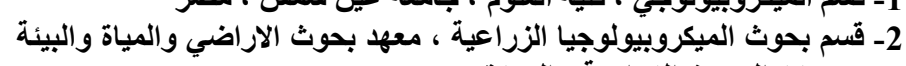

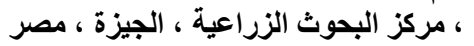

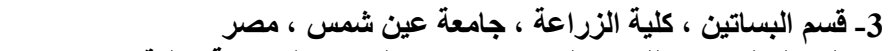

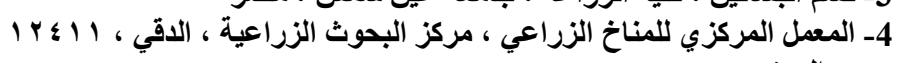

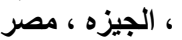

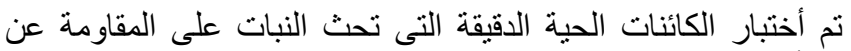

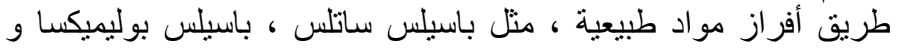

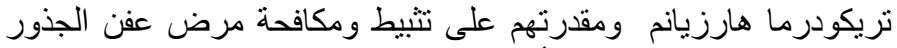

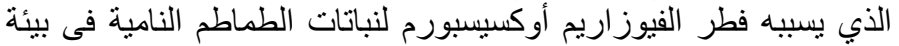

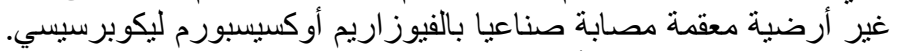

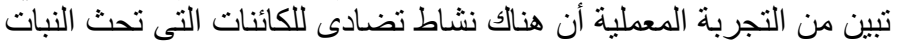

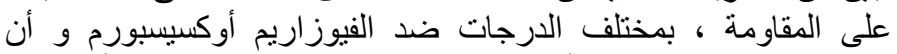

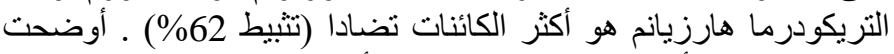
التجارب الحقلية أن الباسيلس بوليميكسا هو أفئر أفضل كائن مؤثر في إنخفاض

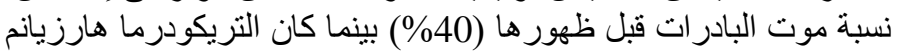

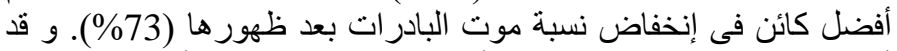

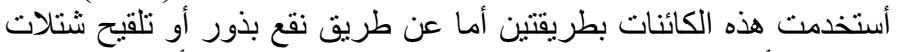

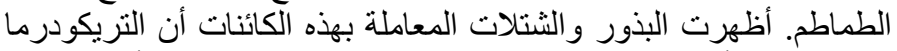

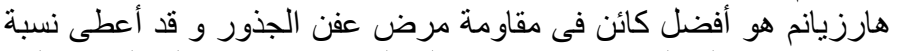

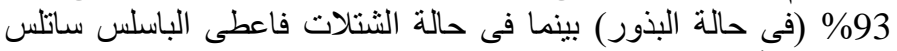

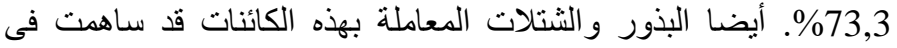

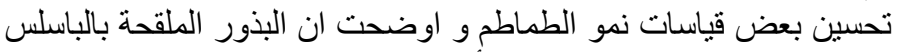

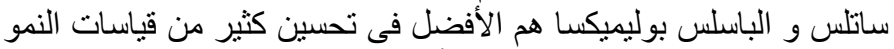

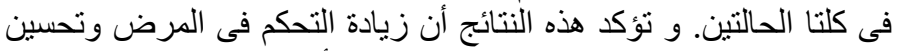

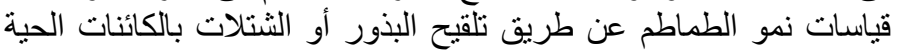

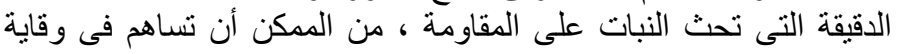

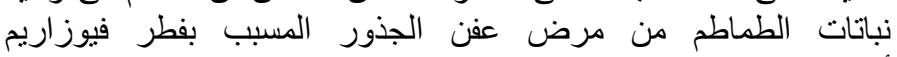

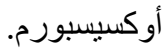

